\title{
MODEL PENGUKURAN KONDISI AWAL SEBAGAI DASAR PENGEMBANGAN PROGRAM PEMBERDAYAAN MASYARAKAT BERKELANJUTAN, STUDI KASUS: KAWASAN WISATA PANTAI BARU, KABUPATEN BANTUL
}

\author{
Djarot Purbadi \\ Program Studi Arsitektur, Fakultas Teknik \\ Universitas Atma Jaya Yogyakarta \\ Email: purbadi@mail.uajy.ac.id
}

\begin{abstract}
ABSTRAK
Kegiatan pengabdian pada masyarakat pada hakekatnya adalah implementasi ilmu pengetahuan dan teknologi pada situasi nyata dalam kehidupan masyarakat. Umumnya kegiatan pengabdian pada masyarakat oleh perguruan tinggi sampai saat ini umumnya bersifat jangka pendek. Idealnya, kegiatan pengabdian pada masyarakat adalah bersifat jangka panjang agar manfaat dan dampaknya signifikan dan dapat diukur dengan pendekatan yang rasional. Kegiatan pengabdian pada masyarakat sebaiknya diawali dengan pengukuran kondisi awal sebagai titik awal suatu perubahan jangka panjang dari skenario perubahan jangka panjang. Tulisan ini menampilkan model pengukuran kondisi awal suatu kawasan dengan pendekatan rasional berdasarkan aspek MSPD (Marketability, Sustainability, Participatory, Disaster Mitigation) sebagai dasar bagi pengembangan suatu kawasan dalam skenario perubahan jangka panjang. Model MSPD diterapkan pada kasus kawasan wisata Pantai Baru di pesisir Kabupaten Bantul. Tulisan ini menampilkan, penilaian kondisi awal menggunakan kriteria MSPD dapat menjadi dasar untuk penyusunan program pengembangan kawasan sesuai kebutuhan dalam lima tahun pada kawasan wisata Pantai Baru.
\end{abstract}

Kata kunci: Pengukuran Kondisi Awal, Pantai Baru, Pengabdian Masyarakat Berkelanjutan.

Measurement of Initial Condition As A Basis for Developing Sustainable Community Development Program, Case Study: Pantai Baru Coastal Tourism Area, Regency Bantul

\begin{abstract}
Community service activities is essentially the implementation of science and technology in real situations in the life of society. Generally, community service activities by universities until today generally are short term. Ideally, community service activities are long-term so that the benefits and impact significantly and can be measured with a rational approach. Community service activities should start by measuring the initial conditions as a starting point for a long-term change of long-term change scenario. This paper displays measurement model initial conditions of a region with a rational approach based on aspects MSPD (Marketability, Sustainability, Participatory, Disaster Mitigation) as the basis for the development of an area in the scenario of long-term change. MSPD models applied in the case of Pantai Baru tourist area in the coastal district of Bantul. This paper displays, the initial condition assessment using the criteria MSPD can be the basis for the preparation of regional development programs as needed within five years at the Pantai Baru tourist area.
\end{abstract}

Keywords: Measurement Initial Condition, Pantai Baru, Sustainable Community Services. 


\section{LATAR BELAKANG}

Perguruan tinggi di Indonesia wajib melaksanakan Tridharma Perguruan Tinggi yang isinya adalah Pendidikan, Penelitian dan Pengabdian pada Masyarakat. Atas dasar ketentuan Tri Dharma, maka Perguruan Tinggi adalah tempat belajar ilmu pengetahuan, tempat mengembangkan ilmu pengetahuan dan teknologi, yang akhirnya harus diterapkan dalam kehidupan masyarakat guna mendorong pencapaian kemajuan dan kesejahteraan serta daya saing bangsa. Perguruan tinggi memiliki kedudukan dan peran yang strategis bagi suatu bangsa atau negara.

Kegiatan pengabdian pada masyarakat pada umumnya dilakukan civitas akademika universitas, intinya adalah menerapkan ilmu pengetahuan dan teknologi untuk membantu masyarakat mengembangkan diri menuju kesejahteraan. Kegiatan pengabdian pada masyarakat adalah salah satu ujung tombak eksistensi sebuah perguruan tinggi atau universitas. Makin tinggi intensitas dan keberhasilan kegiatan pengabdian pada masyarakat, maka kehidupan masyarakat makin terbantu, kemajuannya semakin berkembang dan berkualitas. Artinya, kegiatan pengabdian pada masyarakat merupakan salah satu kegiatan strategis bagi perguruan tinggi.

Pengamatan terhadap kegiatan pengabdian pada masyarakat yang dilakukan secara acak menunjukkan bahwa dalam kegiatan pengabdian pada masyarakat pelaku kegiatan (civitas akademika) berusaha masuk ke dalam kehidupan masyarakat secara fisik dan intelektual, khususnya kelompok masyarakat tertentu secara intens. Kedekatan antara pelaku kegiatan dengan kelompok masyarakat (mitra pengabdian) merupakan salah satu syarat keberhasilan kegiatan. Kedekatan pelaku dengan mitra pengabdian menjadi penting karena merupakan pintu masuk bagi adanya program dan kegiatan yang tepat dan direncanakan bagi mitra pengabdian yang harus memperoleh manfaat langsung. Tanpa hubungan yang dekat dan intens, kegiatan pengabdian pada masyarakat kehilangan roh sejatinya, sebab tidak berakar pada kebutuhan mitra pengabdian, yang diharapkan menerima manfaat serta berkembang kehidupannya secara lebih baik.

Keberhasilan kegiatan pengabdian masyarakat diukur dari terjadinya manfaat dan dampak positif bagi mitra pengabdian (masyarakat atau kelompok tertentu), berupa perubahan aspek tertentu kehidupan mereka dalam jangka pendek maupun jangka panjang. Perubahan dapat terjadi pada aras abstrak hingga konkrit, mulai dari perubahan nilai-nilai, mindset, perilaku, hingga lingkungan kehidupan berupa benda-benda fisik. Perubahan yang diharaopkan adalah menuju pada peningkatan kualitas kehidupan masyarakat, khususnya kesejahteraan, kebudayaan, kualitas sumberdaya manusia, serta kelestarian alam. Artinya, sangatlah penting perubahan yang terjadi pada manusia dan kehidupannya seiring sejalan dengan pelestarian alam dan lingkungan.

Kegiatan pengabdian pada masyarakat pada umumnya bertolak dari sebuah titik awal tertentu dengan pendekatan yang khas. Minimal ada dua pendekatan yang mengawali titik kegiatan pengabdian pada masyarakat, yaitu [1] pendekatan empiris dan [2] pendekatan teoritis. Pendekatan empiris banyak dilakukan, khususnya untuk menciptakan kedekatan dan untuk memperoleh data lapangan yang dianalisis guna menemukan permasalahan spesifik mitra pengabdian. Pendekatan empiris berusaha mengumpulkan data lapangan untuk dianalisis dan menghasilkan problema umum dan problema spesifik yang ada di kalangan mitra pengabdian. Hasil pendekatan ini berupa rumusan permasalahan dan berbagai hal yang menjadi kebutuhan mitra pengabdian. Dapat dikatakan, permasalahan mitra menjadi titik awal penyusunan program dan kegiatan pengabdian masyarakat, baik yang bersifat jangka pendek maupun jangka panjang. 
Pendekatan empiris banyak dilakukan, dengan keyakinan bahwa data lapangan dapat dianalisis untuk diperoleh rumusan permasalahan spesifik pada mitra pengabdian yang menjadi titik berangkat suatu program pengabdian pada masyarakat. Setelah diperoleh permasalahan spesifik sesuai kebutuhan mitra pengabdian, maka tim pengabdian segera menyusun rencana aksi berupa program intervensi untuk mengatasi permasalahan mitra. Artinya, program dan kegiatan pengabdian masyarakat yang disusun diharapkan sungguh berbasis pada kondisi, kebutuhan dan permasalahan mitra pengabdian. Tujuannya adalah agar program dan kegiatan pengabdian pada masyarakat dapat tepat sasaran, berdampak seperti yang diharapkan yaitu perubahan pada mitra pengabdian.

Pendekatan teoritis juga dilakukan dengan cara pelaku pengabdian berbekal teori tertentu dan melakukan investigasi lapangan untuk memperoleh pemahaman tentang kondisi, kebutuhan dan permasalahan mitra. Pendekatan teoritis cenderung melihat kondisi awal sebagai bagian dari perkembangan jangka panjang dengan ukuran tertentu yang ditetapkan. Pendekatan teoritis menggunakan instrumen yang diturunkan dari teori untuk mengukur aspek-aspek tertentu dari kawasan pengabdian pada masyarakat sampai menemukan nilai dari aspek tertentu yang menunjukkan status kawasan pada saat diukur.

Keterangan tentang status kawasan pada saat diukur sangat penting, sebab menjadi dasar untuk memahami kondisi saat tertentu dan memikirkan program atau kegiatan yang tepat bagi pengabdian masyarakat yang akan dilaksanakan. Pada sisi yang lain, posisi nilai tertentu dapat menjadi titik tolak dan inspirasi jenis kegiatan apa yang tepat untuk melakukan perubahan ke status tertentu yang lebih baik. Artinya, pendekatan teoritis semacam ini memberi kerangka berpikir secara lebih spesifik terkait dengan tindakan intervensi yang akan dikembangkan agar status aspek tertentu meningkat.

Artikel ini memaparkan pendekatan teoritis sebagai titik awal dan diwujudkan menjadi pengukuran kondisi awal suatu kawasan wisata pantai (kasus tulisan ini adalah Pantai Baru di Kabupaten Bantul) yang akan digunakan sebagai tempat pengabdian pada masyarakat selama beberapa tahun. Pengukuran awal merupakan bagian pertama dari program kegiatan pengabdian pada masyarakat berpola multi-years yang akan dilakukan dalam periode waktu sekitar 5 tahun ke depan di kawasan wisata Pantai Baru di pesisir selatan Kabupaten Bantul.

Tim berpikir bahwa pengukuran kondisi awal merupakan salah satu langka penting yang harus dilakukan agar kondisi awal dapat dikenali secara spesifik dan intervensi yang akan dilakukan lebih tepat dan dalam perkembangannya dapat dilakukan pemantauan dan evaluasi secara rasional. Oleh karenanya, kegiatan pengukuran yang dipaparkan dalam artikel ini menjadi salah satu langkah penting, bahkan sebagai pijakan utama penyusunan program kegiatan yang akan dilakukan secara multi-years pada kawasan pengabdian masyarakat.

Pantai Baru merupakan salah satu pantai berpasir hitam yang berada di Dusun Ngentak, Poncosari, Srandakan, Kabupaten Bantul. Secara geografis Pantai Baru berdekatan dengan pantai Pandansimo dan Pantai Kuwaru, merupakan dua pantai yang telah dikenal oleh masyarakat lebih dahulu. Pantai Baru berada di sebelah timur dari Pantai Kuwaru dan berada di sebelah barat dari Pantai Pandansimo. Pantai Baru mulai dibuka oleh masyarakat Dusun Ngentak dan dikenal oleh masyarakat secara lebih luas sejak tahun 2010. Kawasan wisata Pantai Baru muncul karena adanya keinginan warga masyarakat desa untuk menciptakan kawasan wisata pantai dengan citra positif.

Pantai Baru memiliki aset alam yang menjadi keunggulan destinasi wisata dan aset budaya mengenai aktivitas pariwisata berbasis pantai. Pantai Baru memiliki arti ekonomi, sosial-budaya dan ekologi yang sangat penting bagi kawasan pantai selatan kabupaten Bantul. Pengembangan pariwisata pantai di Bantul juga sejalan dengan Peraturan Daerah Kabupaten Bantul no. 3 Tahun 
2004 Tentang Rencana Induk Pengembangan Pariwisata Daerah Bantul. Perda tersebut memantapkan potensi wisata pantai di Pantai Baru menjadi obyek dan daya tarik wisata (ODTW) yang perlu dikembangkan dengan seksama.

Perkembangan kawasan wisata Pantai Baru cukup pesat, namun dengan pola spontan dan gagasan acak dari para pelaku kegiatannya. Dinas Pariwisata Bantulk berkehendak menata kawasan wisata Pantai Baru agar menjadi lebih baik. Sejalan dengan kondisi tersebut, terdapat peluang untuk melakukan kegiatan intervensi membantu masyarakat setempat untuk mengembangkan kawasan wisata Pantai Baru dengan arah yang jelas.

Kajian pariwisata sebagai bentuk kajian yang berfokus pada kawasan wisata menjadi potensi yang perlu digunakan untuk membantu kawasan wisata Pantai Baru berkembang secara terarah dan semakin berkualitas. Kajian wisata yang berfokus pada paket-paket wisata akan secara langsung menyentuh unsur-unsur kunci pada suatu kawasan wisata, menemukan permasalahannya dan membantu pengarahan perkembangan ke depan dalam jangka waktu tertentu. Kajian pariwisata memberi peluang untuk pengembangan berbasis potensi kawasan dan kebutuhan pasar dengan dilandasi konsep pelestarian alam, budaya dan kehidupan sosial masyarakat secara berkelanjutan.

Tujuan dari program pengabdian pada masyarakat adalah mendampingi perubahan dan perkembangan kawasan wisata secara menyeluruh, pada aspek sosial, budaya, ekonomi, dan ekologi. Program intervensi yang dimunculkan bertolak dari analisis kebutuhan mitra pengabdian, secara jangka pendek maupun jangka panjang. Idealnya, program pengabdian pada masyarakat merupakan program kemitraan berkelanjutan, agar mitra pengabdian memperoleh manfaat jangka panjang dan bersifat relatif permanen. Pada akhirnya, lewat pengabdian pada masyarakat, diharapkan perkembangan masyarakat dapat dilakukan sendiri secara mandiri oleh masyarakat.

\section{MASALAH}

Permasalahan pada kawasan wisata Pantai Baru adalah bagaimana mengembangkan kawasan Pantai Baru menjadi destinasi wisata sesuai dengan kondisi, potensi lokal dan permasalahan yang ada terarah pada upaya pemberdayaan masyarakat dan kelestarian lingkungan secara berkelanjutan. Kawasan wisata Pantai Baru seyogyanya dikembangkan menjadi kawasan wisata yang berstandar nasional hingga internasional. Permasalahan kawasan wisata Pantai Baru dilihat dengan kacamata kajian pariwisata, yang berfokus pada tiga aspek, yaitu pemasaran, partisipasi, keberlanjutan. Khusus untuk wilayah kabupaten Bantul, diperlukan satu tambahan lagi, yaitu mitigasi bencana.

\section{METODE PELAKSANAAN}

Tim pengabdian masyarakat berkeyakinan bahwa kegiatan pengabdian pada masyarakat harus diawali dengan pemahaman mitra dan permasalahan spesifiknya. Pemahaman kondisi, situasi dan permasalahan mitra pengabdian dilakukan secara mendalam dan terukur. Oleh karenanya, pengukuran dilakukan dengan memilih konsep-konsep yang relevan dengan program pengembangan kawasan wisata. Pengukuran awal yang dilakukan pada kasus Pantai Baru menggunakan landasan konsep Marketability, Sustainability, Participation dan Disaster Management yang dirancang dan digabungkan menjadi satu instrumen. Konsep-konsep tersebut digunakan untuk mengukur status paket-paket wisata yang dikembangkan di Pantai Baru, baik eksisting maupun yang mungkin diangkat karena keunikan kondisi alam, sosial dan budaya masyarakatnya. 
Bagan Kerangka Penilaian Kawasan Wisata

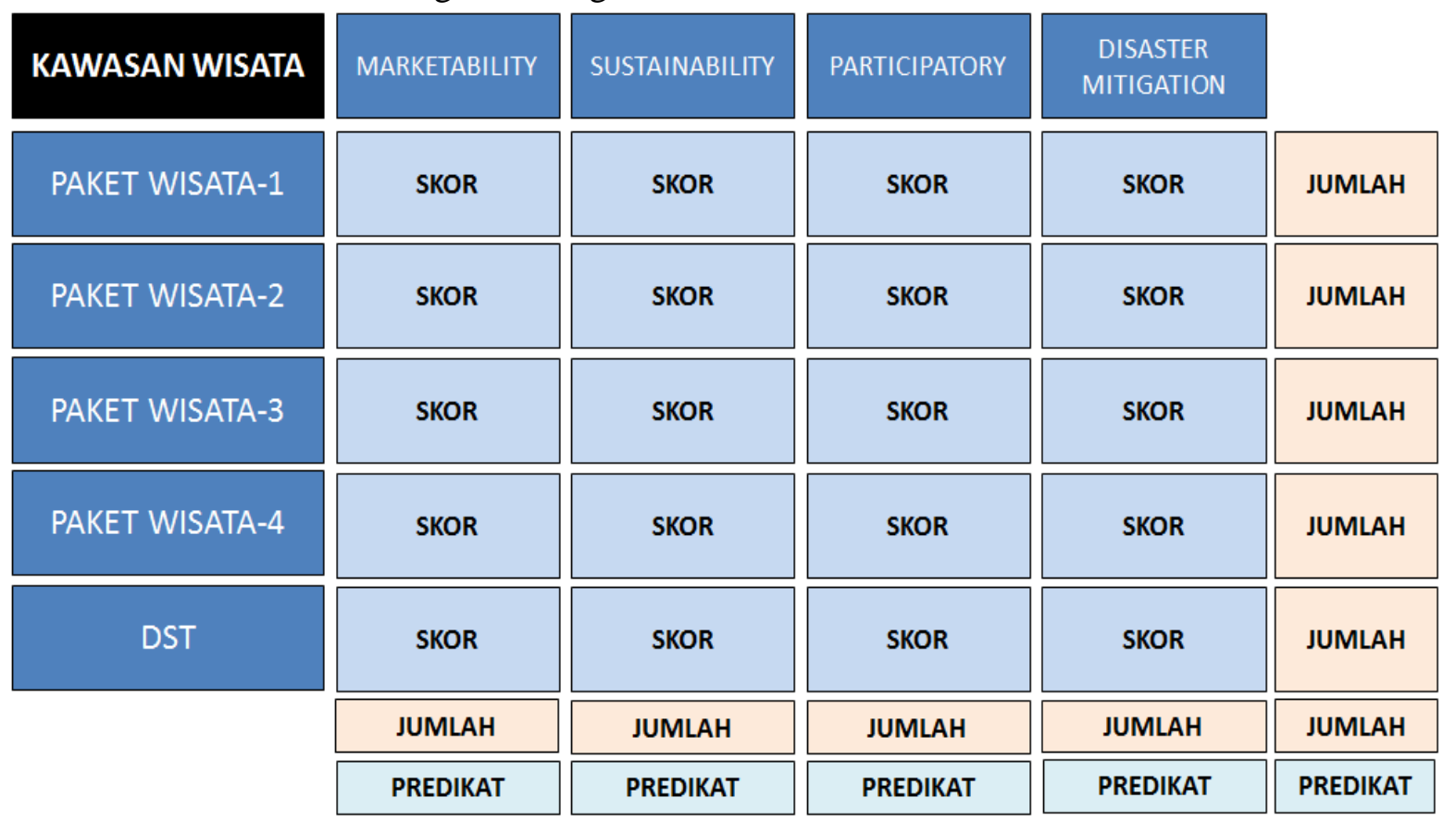

Sumber: Pemikiran Tim Inspect, 2016

Model pengukuran kuantitatif kondisi awal kawasan wisata dengan pendekatan rasional mengangkat aspek MSPD (Marketability, Sustainability, Participatory, Disaster Mitigation) dapat menjadi kunci bagi pengembangan suatu kawasan wisata dalam jangka panjang. Ketiga aspek MSPD merupakan aspek-aspek kunci yang menjadi kriteria dan tolok ukur status suatu kawasan wisata dengan unsur-unsur kepariwisataan yang ada di dalamnya.

Marketability terkait pemasaran obyek wisata merupakan elemen kunci yang harus diperhatikan dalam pengelolaan kawasan wisata agar berkembang secara mandiri dalam jangka panjang. Sustainability juga merupakan unsur penting yang menyangkut kelestarian alam (Siswantoro, Anggoro, \& Sasongko, 2012). Konservasi harus ada dalam kegiatan pariwisata (Permana, Santosa, \& Soemardiono, 2010) terkait konservasi alam dan budaya. Partisipasi menjadi unsur yang mutlak harus ada, sebab keterlibatan masyarakat sangat menentukan keberhasilannya dalam jangka panjang (Raharjana, 2012) (Dewi, Fandeli, \& Baiquni, 2013). Partisipasi sangat penting sejak awal, tahap persiapan maupun pengelolaan selanjutnya secara berkesinambungan (Dewi, 2014)(Sutrisno, 2016). Penataan kawasan wisata juga harus memperhatikan aspek kebencanaan (disaster mitigation), seperti halnya pada penataan ruang perkotaan (Priatmodjo, 2011).

Agar penilaian dapat memperoleh hasil yang rinci, maka aspek diturunkan menjadi parameter dan rincian unsurnya. Selanjutnya, dari rincian tentang unsur dilakukan penetapan nilai, seperti pada contoh di bawah ini, dikembangkan untuk aspek Marketability, Sustainability, Participatory dan Disaster Mitigation. 


\section{Contoh Tabel Rincian Parameter, Unsur dan Nilai}

\begin{tabular}{|c|c|c|c|c|c|c|}
\hline \multicolumn{7}{|c|}{ 1. PEMASARAN (MARKETABILITY) } \\
\hline \multirow{2}{*}{ PARAMETER } & \multirow{2}{*}{ RINCIAN UNSUR } & \multicolumn{5}{|c|}{$\begin{array}{l}\text { NILAI DAN INDIKATORNYA } \\
\end{array}$} \\
\hline & & NILAI-1 & NILAI-2 & NILAI-3 & NILAI-4 & NILAI-5 \\
\hline $\begin{array}{l}\text { A. Pengemasan Produk } \\
\text { Wisata }\end{array}$ & $\begin{array}{l}\text { Bentuk kemasan barang } \\
\text { ataupun jasa-jasa wisata } \\
\text { yang ditampilkan }\end{array}$ & $\begin{array}{l}\text { Bila belum ada } \\
\text { kesepakatan bentuk dan } \\
\text { tampilan aneka jenis } \\
\text { produk wisata }\end{array}$ & $\begin{array}{l}\text { Bila sudah ada pelaku } \\
\text { yang membuat standar } \\
\text { untuk tampilan aneka } \\
\text { jenis produk wisata, } \\
\text { namun belum untuk } \\
\text { semua produknya }\end{array}$ & $\begin{array}{l}\text { Bila sudah ada } \\
\text { standarisasi tampilan } \\
\text { jenis produk, namun } \\
\text { untuk jenis usaha } \\
\text { tertentu }\end{array}$ & $\begin{array}{l}\text { Bila sudah ada } \\
\text { kesepakatan dan } \\
\text { standarisasi bentuk dan } \\
\text { semua jenis produk } \\
\text { wisata }\end{array}$ & $\begin{array}{l}\text { Bila sudah ada } \\
\text { kesepakatan dan } \\
\text { standarisasi bentuk dan } \\
\text { semua jenis produk } \\
\text { wisata dan } \\
\text { kesinambungan tematik }\end{array}$ \\
\hline B. Model Promosi & $\begin{array}{l}\text { Pilihan berbagai media } \\
\text { promosi }\end{array}$ & $\begin{array}{l}\text { Bila belum menggunakan } \\
\text { aneka model promosi }\end{array}$ & $\begin{array}{l}\text { Bila sudah ada pelaku } \\
\text { yang menggunakan } 1 \\
\text { jenis model promosi }\end{array}$ & $\begin{array}{l}\text { Bila sudah ada pelaku } \\
\text { yang menggunakan lebih } \\
\text { dari } 1 \text { media promosi }\end{array}$ & $\begin{array}{l}\text { Bila penggunaan berbagai } \\
\text { model promosi untuk } \\
\text { seluruh pelaku telah } \\
\text { dikoordinir }\end{array}$ & $\begin{array}{l}\text { Bila sudah menggunakan } \\
\text { berbagai media promosi } \\
\text { dan memanfaatkan } \\
\text { bebagai jaringan } \\
\text { komunikasi yang } \\
\text { terkoordinasi } \\
\end{array}$ \\
\hline $\begin{array}{l}\text { C. Sistem informasi } \\
\text { wisata }\end{array}$ & $\begin{array}{l}\text { Kombinasi dari teknologi } \\
\text { informasi dan aktivitas } \\
\text { orang yang menggunakan } \\
\text { teknologi itu untuk } \\
\text { mendukung aktifitas } \\
\text { wisata }\end{array}$ & $\begin{array}{l}\text { Bila belum menggunakan } \\
\text { sistem informasi }\end{array}$ & $\begin{array}{l}\text { Bila sudah menggunakan } \\
1 \text { macam sistem } \\
\text { informasi oleh pelaku } \\
\text { wisata setempat }\end{array}$ & $\begin{array}{l}\text { Bila sudah menggunakan } \\
\text { aneka macam sistem } \\
\text { informasi namun } \\
\text { digerakkan oleh pihak } \\
\text { luar }\end{array}$ & $\begin{array}{l}\text { Bila sudah menggunakan } \\
\text { aneka bentuk sisem } \\
\text { informasi wisata dan } \\
\text { hanya digerakkan oleh } \\
\text { pelaku wisata setempat }\end{array}$ & $\begin{array}{l}\text { Bila sudah menggunakan } \\
\text { aneka bentuk sistem } \\
\text { informasi dan digerakkan } \\
\text { mandiri oleh pelaku } \\
\text { wisata setempat dan } \\
\text { aenka stkae holder }\end{array}$ \\
\hline D. Distribusi pemasaran & $\begin{array}{l}\text { Jangkauan relasi } \\
\text { pemasaran produk } \\
\text { wisata }\end{array}$ & $\begin{array}{l}\text { Bila jangkauan relasi } \\
\text { pemasaran masih sangat } \\
\text { lokal (tingkat dalam } \\
\text { kabupaten dan } \\
\text { sekitarnya) }\end{array}$ & $\begin{array}{l}\text { Bila jangkauan relasi } \\
\text { pemasaran masih lokal } \\
\text { (tingkat antar kabupaten } \\
\text { dan sekitarnya) }\end{array}$ & $\begin{array}{l}\text { Bila jangkauan relasi } \\
\text { pemasaran mencapai } \\
\text { propinsi- propinsi lain } \\
\text { yang ada di satu pulau }\end{array}$ & $\begin{array}{l}\text { Bila jangkauan relasi } \\
\text { pemasaran mencapai } \\
\text { tingkat nasional }\end{array}$ & $\begin{array}{l}\text { Bila jangkauan relasi } \\
\text { pemasaran mencapai } \\
\text { tingkat internasional }\end{array}$ \\
\hline
\end{tabular}

Sumber: Analisis Tim Inspect, 2016

Berikutnya, dari tabel tersebut di atas dikembangkan program intrevensi yang tepat untuk digunakan ke arah pengembangannya terkait dengan setiap nilai. Misalnya, dari nilai-1 hendak berkembang menuju nilai-2 ada sebutan dengan kode [1-2], atau dari nilai-2 ke nilai-3 ada program dengan disebutkan kode [2-3], demikian seterusnya. Selanjutnya, jika sudah dirumuskan program intervensi terkait, maka dilakukan pemerincian lebih lanjut menjadi jenis kegiatan spesifik yang sesuai untuk dikembangkan. Dengan kata lain, perubahan secara gradual telah dipikirkan terkait dengan program dan kegiatan intervensi yang harus diadakan, bahkan sejak dari tahap penentuan nilai.

\section{Contoh Tabel Nilai dan Program Pengembangan}

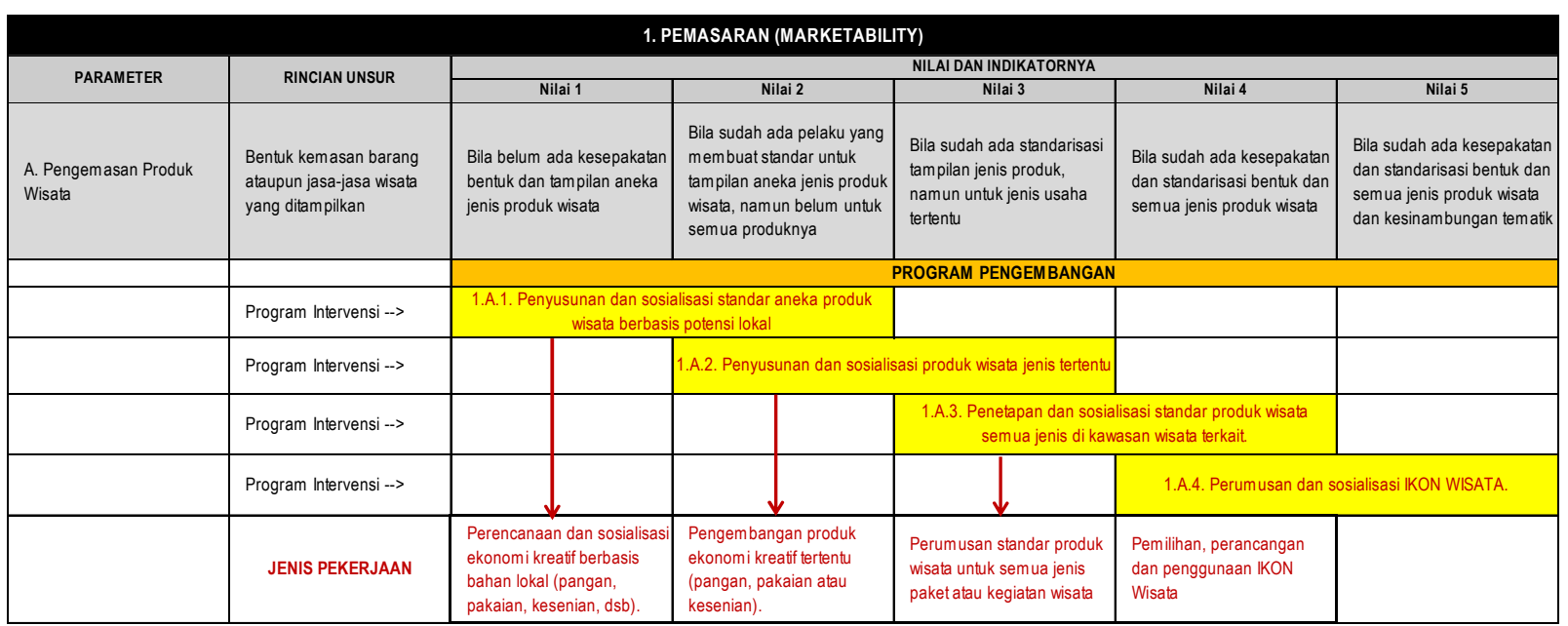

Sumber: Analisis Tim Inspect, 2016 


\section{(2) Teknik Pengumpulan Data}

Kawasan wisata Pantai Baru memiliki paket-paket wisata sejumlah 9 paket, yaitu: [1] Wisata Pantai, [2] Wisata Kuliner, [3] Wisata Teknologi Angin dan Surya, [4] Wisata Teknologi Biogas, [5] Wisata Permainan Anak-anak, [6] Wisata Pengelolaan Sampah Lingkungan, [7] Wisata Pertanian Lahan Berparis, [8] Wisata Konservasi Penyu, dan [9] Wisata Seni Budaya. Semua paket wisata tersebut dievaluasi dan dinilai berdasarkan observasi lapangan dan wawancara. Hasil observasi dan wawancara didiskusikan di dalam tim untuk menetapkan angka (skor) pada setiap paket wisata dan aspek-aspek MSPD yang terkait. Tim memberikan nilai pada tabel yang sudah disediakan, untuk memasukkan skor-skor pada sel-sel yang sudah ditentukan. Hasil penilaian menunjukkan nilai status pada aspek Marketability, Sustainability, Participatory dan Disaster Mitigation maupun hasil keseluruhan. Selanjutnya, pada jumlah nilai diletakkan predikat yang sesuai dengan kondisi terukur, menggunakan kategori berdasarkan nilai yang diperoleh, yaitu predikat: Embrio, Rintisan, Tumbuh dan Mandiri.

\section{(3) Teknik Analisis Data}

Teknik analisis data menggunakan aplikasi excel agar mudah dilakukan perhitungan secara kuantitatif. Caranya, memasukkan data skor ke dalam tabel-tabel, dengan modifikasi rumus, diperoleh nilai tertentu yang menunjukkan hasil observasi lapangan dan wawancara lapangan. Pemberian skor dilakukan lewat diskusi tim, sehingga subyektivitas dapat relatif ditekan. Artinya, hasil penilaian yang diperoleh diduga kuat mencerminkan keadaan sebenarnya, termasuk pemberian predikat status kawasan saat pengukuran (embrio, rintisan, tumbuh dan mandiri) terkait dengan nilai dan kategori predikat yang dirumuskan.

(4) Lokasi, waktu, dan durasi kegiatan.

Lokasi pengukuran dilakukan di kawasan wisata Pantai Baru, dilakukan oleh sejumlah 7 orang, yang telah melakukan observasi derta wawancara dengan pihak-pihak yang terkait di lapangan.

\section{HASIL DAN PEMBAHASAN}

Hasil pengukuran yang dilakukan dengan model intrumen MSPD menunjukkan bahwa kawasan wisata Pantai Baru masih dalam STATUS RINTISAN. Dari tabel penilaian terlihat bahwa aspek pemasaran mencapai nilai 2,28 (rintisan), aspek keberlanjutan mencapai nilai 2,42 (rintisan), aspek partisipasi memperoleh nilai 2,75 (rintisan), dan aspek mitigasi bencana menperoleh nilai 2,45 (rintisan). Perolehan nilai secara parsial (per-aspek) dan akumulasi keseluruhan menunjukkan bahwa program intervensi untuk pengembangan terhadap kawasan wisata Pantai Baru masih harus banyak dilakukan.

Mengingat nilai secara parsial maupun keseluruhan yang diperoleh Kawasan Pantai Baru adalah terendah 2,28 (rintisan) dan tertinggi adalah 2,75 (rintisan), maka program intervensi yang layak dikembangkan selama beberapa tahun (misal 5 tahun) adalah meliputi program intervensi atau program kegiatan dengan kode [2-3], [3-4], dan [4-5]. Perolehan tersebut menjadi dasar untuk menyusun tabel program intervensi multi-years, yang berbasis pada kondisi dan kebutuhan lokal sekaligus menjawab kebutuhan jangka panjang yang terencana. 
Tabel Hasil Penilaian Status Terkini Kawasan Wisata Pantai Baru

\begin{tabular}{|c|c|c|c|c|c|c|c|c|c|c|c|c|c|c|c|c|c|c|c|c|c|}
\hline \multicolumn{22}{|c|}{ HASIL PENILAIAN PANTAI BARU } \\
\hline \multicolumn{2}{|r|}{ OBYEK DAN PAKET WISATA PANTAI BARU } & \multicolumn{5}{|c|}{$\begin{array}{l}\text { 1. PEMASARAN } \\
\text { (MARKETABILITY) }\end{array}$} & \multicolumn{7}{|c|}{ 2. KEBERLANJUTAN (SUSTAINABILITY) } & \multicolumn{5}{|c|}{$\begin{array}{l}\text { 3. PARTISIPASI } \\
\text { (PARTICIPATORY) }\end{array}$} & \multicolumn{3}{|c|}{$\begin{array}{l}\text { 4. MITIGASI BENCANA } \\
\text { (DISASTER } \\
\text { MITIGATION) }\end{array}$} \\
\hline NO & ASPEK PENILAIAN & A & $B$ & C & $\mathrm{D}$ & Sub total & A & $B$ & C & $\mathrm{D}$ & $E$ & $\mathrm{~F}$ & Sub total & A & $B$ & $\mathrm{C}$ & $\mathrm{D}$ & Sub total & A & B & Sub total \\
\hline 1 & 1. WISATA PANTAI & 2 & 3 & 2 & 2 & 2.25 & 2 & 1 & 2 & 4 & 4 & 3 & 2.67 & 4 & 4 & 3 & 3 & 3.50 & 4 & 1 & 2.50 \\
\hline 2 & 2. WISATA KULINER & 2 & 2 & 2 & 2 & 2.00 & 2 & 1 & 1 & 4 & 3 & 3 & 2.33 & 3 & 4 & 2 & 3 & 3.00 & 4 & 1 & 2.50 \\
\hline 3 & 3. WISATA TEKNOLOGI ANGIN DAN SURYA & 3 & 1 & 3 & 2 & 2.25 & 5 & 1 & 5 & 4 & 3 & 5 & 3.83 & 4 & 5 & 2 & 2 & 3.25 & 3 & 3 & 3.00 \\
\hline 4 & 4. WISATA TEKNOLOGI BIOGAS & 3 & 1 & 3 & 2 & 2.25 & 3 & 1 & 4 & 4 & 3 & 3 & 3.00 & 4 & 3 & 2 & 2 & 2.75 & 3 & 3 & 3.00 \\
\hline 5 & 5. WISATA PERMAINAN ANAK-ANAK & 2 & 2 & 2 & 2 & 2.00 & 2 & 1 & 2 & 4 & 2 & 3 & 2.33 & 2 & 4 & 2 & 3 & 2.75 & 3 & 2 & 2.50 \\
\hline 6 & 6. WISATA PENGELOLAAN SAMPAH KAWASAN & 2 & 2 & 3 & 3 & 2.50 & 3 & 1 & 3 & 4 & 2 & 3 & 2.67 & 4 & 4 & 2 & 2 & 3.00 & 3 & 2 & 2.50 \\
\hline 7 & 7. WISATA TEKNOLOGI PERTAMBAKAN & 2 & 2 & 3 & 4 & 2.75 & 1 & 1 & 1 & 2 & 1 & 1 & 1.17 & 2 & 1 & 2 & 2 & 1.75 & 1 & 1 & 1.00 \\
\hline 8 & 8. WISATA PERTANIAN LAHAN BERPASIR & 2 & 2 & 2 & 2 & 2.00 & 2 & 1 & 2 & 2 & 3 & 3 & 2.17 & 3 & 3 & 2 & 2 & 2.50 & 3 & 2 & 2.50 \\
\hline 9 & 9. WISATA KONSERVASI PENYU & 3 & 4 & 5 & 3 & 3.75 & 1 & 1 & 1 & 3 & 3 & 3 & 2.00 & 3 & 3 & 2 & 2 & 2.50 & 3 & 2 & 2.50 \\
\hline \multirow[t]{9}{*}{10} & 10. WISATA SENI DAN BUDAYA & 1 & 1 & 1 & 1 & 1.00 & 1 & 1 & 1 & 3 & 3 & 3 & 2.00 & 3 & 3 & 2 & 2 & 2.50 & 3 & 2 & 2.50 \\
\hline & & & & & & 2.28 & & & & & & & 2.42 & & & & & 2.75 & & & 2.45 \\
\hline & & & & & \multicolumn{3}{|c|}{ RINTISAN } & & & & & \multicolumn{3}{|c|}{ RINTISAN } & & & \multicolumn{3}{|c|}{ RINTISAN } & \multicolumn{2}{|r|}{ RINTISAN } \\
\hline & & & & & & & & & & & & & & & & & & & & & TAL NILAI KAWASAN \\
\hline & & & & & \multicolumn{7}{|c|}{ SKALA NILAI DAN SEBUTAN } & & & & & & & & & \multicolumn{2}{|c|}{2.47} \\
\hline & & & & & 1 & - & 1.99 & & \multicolumn{3}{|c|}{ EMBRIO } & & & & & & & & & \multicolumn{2}{|r|}{ RINTISAN } \\
\hline & & & & & 2 & - & 2.99 & & \multicolumn{3}{|c|}{ RINTISAN } & & & & & & & & & & \\
\hline & & & & & 3 & - & 3.99 & & \multicolumn{3}{|c|}{ TUMBUH } & & & & & & & & & & \\
\hline & & & & & 4 & - & 5.00 & & \multicolumn{3}{|c|}{ MANDIRI } & & & & & & & & & & \\
\hline
\end{tabular}

Sumber: Analisis Tim Inspect, Juli 2016

Pada tabel-tabel di bawah ini, perubahan berkode [2-3] dilakukan selama 2 tahun kegiatan, sedangkan perubahan dari [3-4] dilakukan selama periode tahun ke tiga, dan perubahan dengan kode [4-5] terjadi selama 2 tahun pada akhir periode 5 tahun. Perumusan program dan kegiatan apa yang harus dikerjakan dapat dilihat lewat tabel utuh nilai dan program yang sudah ditetapkan terlebih dahulu (analisis secara khusus).

Tabel Program dan Kegiatan Pengembangan Pemasaran pada Pantai Baru tahun 2017-2022

\begin{tabular}{|c|c|c|c|c|c|c|c|c|c|c|c|}
\hline \multirow{2}{*}{ 1. PEMASARAN (MARKKETABILITY) } & NLAAI | & INT & TAHUN.1 & & TAHUN.2 & & TAHUN-3 & & TAHUN 4 & & TAHUNS \\
\hline & 228 & [2.3] & & {$[2 \cdot 3]$} & & [B]] & & {$[4.5]$} & & {$[45]$} & \\
\hline A.Pengenasan Prodk Wistab & A & {$[2 \cdot 2]$} & 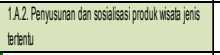 & {$[2.3]$} & 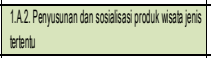 & [B.4] & 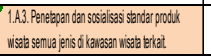 & {$[4.5]$} & 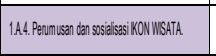 & [45] ] & 1.A4. Perunussndan ssailissai KONWISTTA. \\
\hline 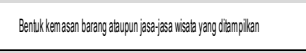 & & & 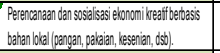 & & 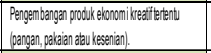 & & 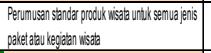 & & 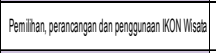 & & 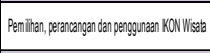 \\
\hline B. llodel Pronosi & B & {$[2 \cdot 3]$} & 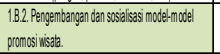 & {$[2.3]$} & 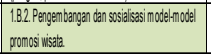 & [3.4] & 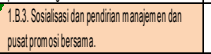 & {$[4.5]$} & 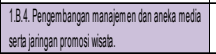 & [45] & 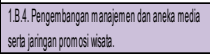 \\
\hline 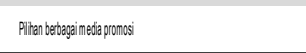 & & & 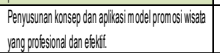 & & 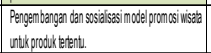 & & 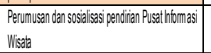 & & 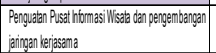 & & 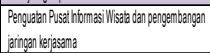 \\
\hline C. Sistem intormasi wisata & c & {$[2 \cdot 2]$} & 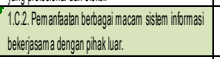 & {$[2 \cdot 3]$} & 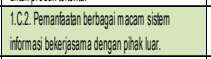 & [3.4] & 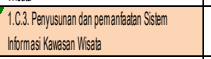 & {$[4.5]$} & 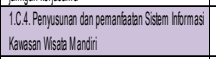 & [45] & 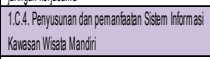 \\
\hline 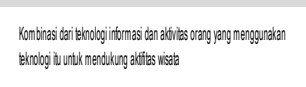 & & & 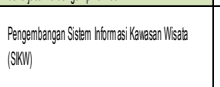 & & 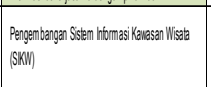 & & 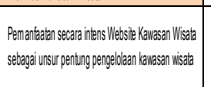 & & 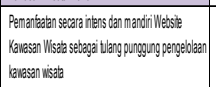 & & 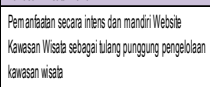 \\
\hline D. Distibus pemassiren & 0 & {$[2 \cdot 3]$} & 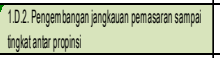 & {$[2 \cdot 2]$} & 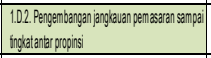 & [34] & 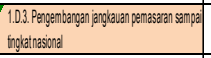 & {$[4.5]$} & 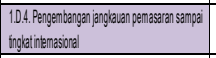 & [4.5] & 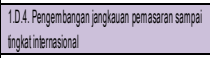 \\
\hline 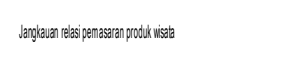 & & & 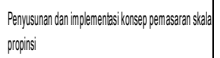 & & 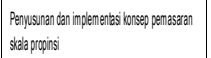 & & 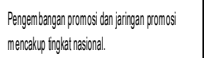 & & 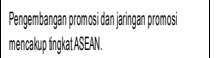 & & 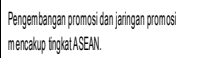 \\
\hline
\end{tabular}

Sumber: Analisis Tim Inspect, 2016 
Tabel Program dan Kegiatan Pengembangan Keberlanjutan pada Pantai Baru tahun 2017-2022

\begin{tabular}{|c|c|c|c|c|c|c|c|c|c|c|c|}
\hline \multirow{2}{*}{ 2. KEBERLANJUTAN (SUSTANABILTY) } & NLLAI & |NT & TAHUN-1 & & TAHUN-2 & & TAHUN-3 & & TAHUN-4 & & TAHUN.5 \\
\hline & 2.42 & [2:3] & & [2:3] & & {$[3-4]$} & & {$[4.5]$} & & {$[4.5]$} & \\
\hline 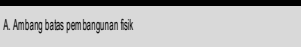 & A & {$[2: 23]$} & 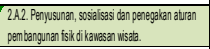 & [2:23] & 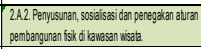 & {$[24]$} & 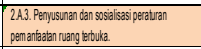 & [45] & 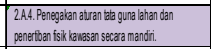 & {$[4.5]$} & 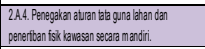 \\
\hline 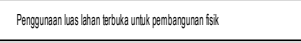 & & & 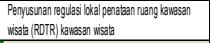 & & 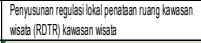 & & 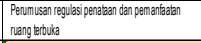 & & 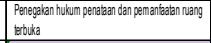 & & 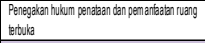 \\
\hline B. Ambang batas jumbla pergyniny & B & [2:23] & 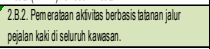 & {$[2: 2]$} & 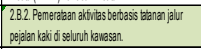 & {$[3-4]$} & 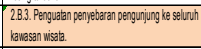 & [45] & 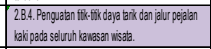 & {$[4.5]$} & 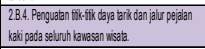 \\
\hline 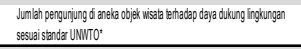 & & & 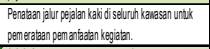 & & 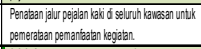 & & 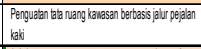 & & 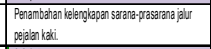 & & 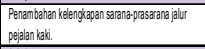 \\
\hline C. Antarng babss suntere daja alam & c & [2:23] & 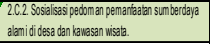 & {$[2 \cdot 3]$} & 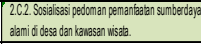 & {$[3-4]$} & 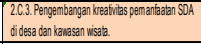 & [4.5] & 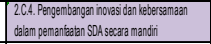 & {$[4.5]$} & 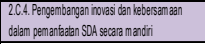 \\
\hline 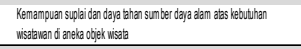 & & & 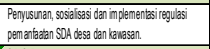 & & 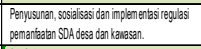 & & 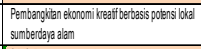 & & 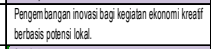 & & 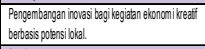 \\
\hline D. Resson nasyadabatseltmpat & 0 & [2:23] & 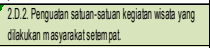 & [2.3] & 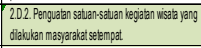 & {$[3-4]$} & 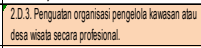 & {$[45]$} & 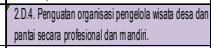 & {$[4.5]$} & 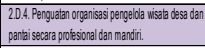 \\
\hline 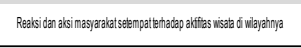 & & & 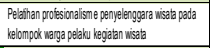 & & 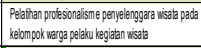 & & 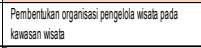 & & 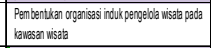 & & 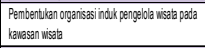 \\
\hline E. Respon wisetran & E & [2:23] & 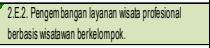 & {$[2.2]$} & 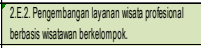 & {$[3-4]$} & 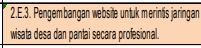 & $4.5]$ & 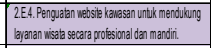 & {$[4.5]$} & 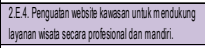 \\
\hline 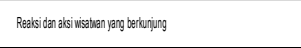 & & & 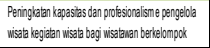 & & 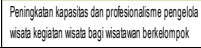 & & 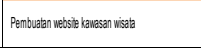 & & 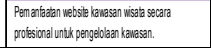 & & 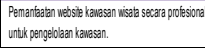 \\
\hline F. Respon nementirlath & $\mathrm{F}$ & {$[2.23]$} & 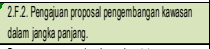 & [2.2] & 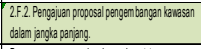 & {$[3-4]$} & 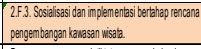 & {$[45]$} & 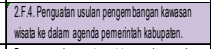 & {$[4.5]$} & 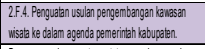 \\
\hline 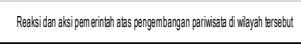 & & & 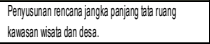 & & 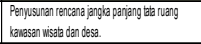 & & 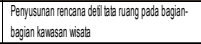 & & 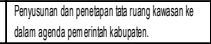 & & 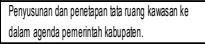 \\
\hline
\end{tabular}

Sumber: Analisis Tim Inspect, 2016

Tabel Program dan Kegiatan Pengembangan Partisipasi pada Pantai Baru tahun 2017-2022

\begin{tabular}{|c|c|c|c|c|c|c|c|c|c|c|c|}
\hline & NLLA & \begin{tabular}{|l|l|l|ll} 
WT \\
\end{tabular} & TAHUN-1 & & TAHUN.2 & & TAHUN:3 & & TAHUN 4 & & TAHUN:5 \\
\hline 3. PARTISIPASI (PARTICIPATORY) & 275 & {$[2.3]$} & & {$[2.3]$} & & [3-4] & & [4.5] & & {$[4.5]$} & \\
\hline 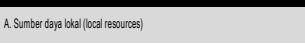 & A & [2-3] & 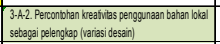 & {$[2 \cdot 3]$} & 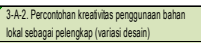 & {$[3-4]$} & 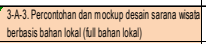 & {$[4.5]$} & 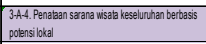 & [4.5] & 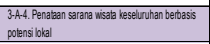 \\
\hline 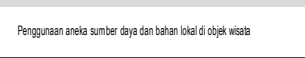 & & & 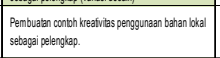 & & 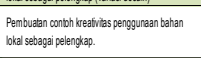 & & 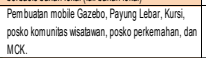 & & 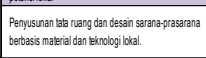 & & 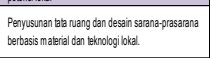 \\
\hline 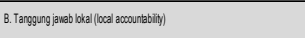 & ${ }^{8}$ & {$[2.3]$} & 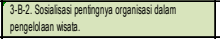 & [2.3] & 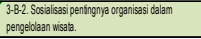 & {$[3-4]$} & 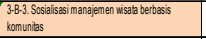 & {$[4.5]$} & 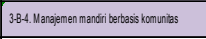 & [1.5] & 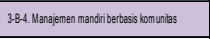 \\
\hline 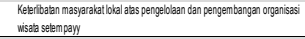 & & & 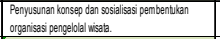 & & 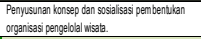 & & 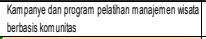 & & 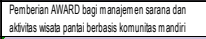 & & 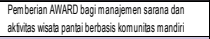 \\
\hline C. Varias daerah setempat (local variey) & $c$ & [2.23] & 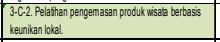 & [2:3] & 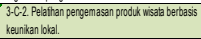 & (3-4) & 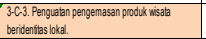 & {$[4.5]$} & 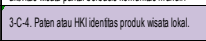 & [1.5] & 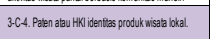 \\
\hline 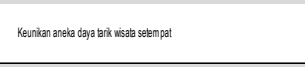 & & & 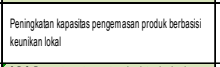 & & 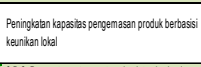 & & 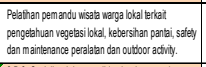 & & 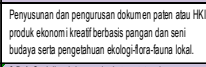 & & 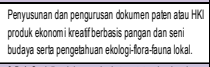 \\
\hline D. Keuntingan ektoromilibal & 0 & {$[2.3]$} & 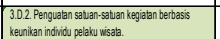 & [2.3] & 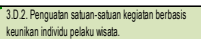 & (3-4)] & 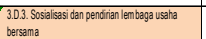 & [4.5] & 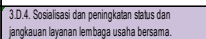 & [1.5] & 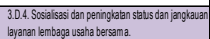 \\
\hline 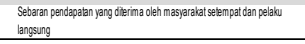 & & & 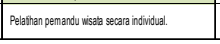 & & 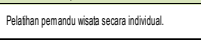 & & 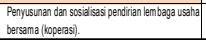 & & 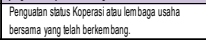 & & 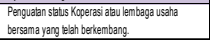 \\
\hline
\end{tabular}

Sumber: Analisis Tim Inspect, 2016

Tabel Program dan Kegiatan Pengembangan Mitigasi Bencana pada Pantai Baru tahun 2017-2022

\begin{tabular}{|c|c|c|c|c|c|c|c|c|c|c|c|}
\hline \multirow{2}{*}{ A.MIIGASIBENCANA(DISASTER WIIIGATION) } & NLAA & NT & TAHNH.1 & & TAHWH:2 & & TAHWHB & & TAHWH & & TAHNWS \\
\hline & 2.5 & {$[2 \cdot 3]$} & & [2:2.] & & [3.4] & & [3.4] & & {$[45]$} & \\
\hline 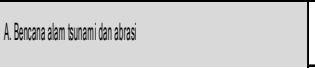 & A & {$[2 \cdot 3]$} & 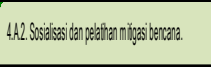 & {$[2 \cdot 2]$} & 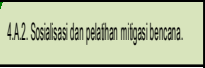 & {$[B .4]$} & 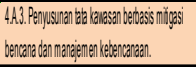 & {$[B-4$} & 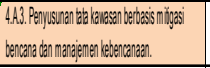 & {$[4.5]$} & 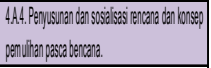 \\
\hline 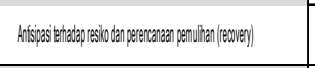 & & & 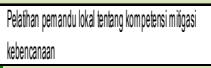 & & 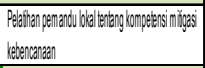 & & 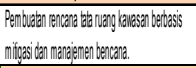 & & 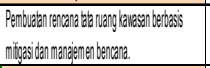 & & 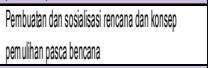 \\
\hline 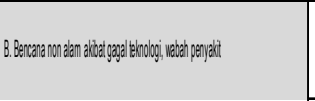 & B & {$[2 \cdot 2]$} & 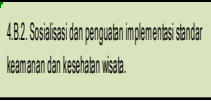 & {$[2: 3]$} & 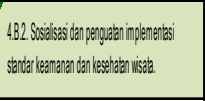 & [B.4] & 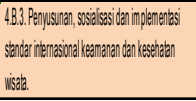 & [BA] & 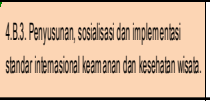 & {$[4.5]$} & 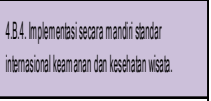 \\
\hline 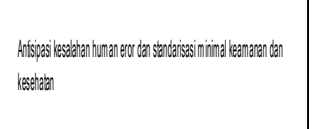 & & & 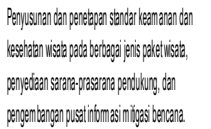 & & 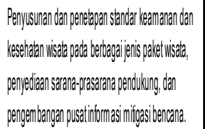 & & 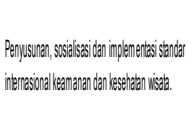 & & 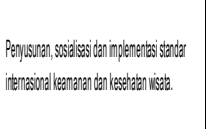 & & 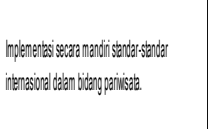 \\
\hline
\end{tabular}

Sumber: Analisis Tim Inspect, 2016

\section{PEMBAHASAN}

Hasil penilaian dengan instrumen MSPD berupa tabel Program dan Kegiatan Tahunan pada 4 aspek yang difokuskan (terlampir di atas) menunjukkan nilai masing-masing aspek. Secara keseluruhan, nilai yang diperoleh pada pengukuran kawasan wisata Pantai Baru berkisar antara 
2,28 sd 2,75. Artinya, status kondisi MSPD pada kawasan wisata Pantai Baru terletak pada posisi predikat RINTISAN. Status rintisan merupakan status di atas EMBRIO, jadi masih diperlukan pengembangan ke tahap TUMBUH dan MANDIRI.

Dalam sistem pengukuran MSPD yang dikembangkan ini, status RINTISAN dapat dikembangkan ke arah MANDIRI melalui pemilihan program dan kegiatan dengan kode [2-3] disambung dengan [3-4] dan dilanjutkan dengan [4-5]. Artinya, penilaian merupakan titik pijak untuk menyusun program intervensi untuk pengembangan yang direncanakan. Penilaian tidak berhenti pada penilaian, melainkan justru menjadi pijakan penyusunan program pengembangan yang bersifat umum ataupun bersifat spesifik (rumusan lebih lanjut). Atas dasar itulah, program pengembangan dapat tersusun secara rinci dan fokus, khususnya memperlihatkan aspek-aspek MSPD yang harus ditangani secara terfokus dan bertahap-berjenjang selama kurun waktu tertentu (misal: lima tahun).

Pemerincian kegiatan pengembangan sesuai aspek tertentu memberi kemungkinan penggarapan aspek secara terfokus. Rumusan dalam tabel merupakan kumpulan gagasan yang menjadi semacam "lorong gagasan pengarah", agar perubahan yang direncanakan sungguh berbasis tema kebutuhan lokal, kondisi lokal serta wawasan perubahan jangka panjang yang terukur. Perumusan jenis kegiatan secara terinci selanjutnya mengacu pada tabel tersebut. Artinya, tema-tema kegiatan yang ada di dalam tabel terlampir sudah mampu mengarahkan pengembangan ke kondisi tertentu yang aspeknya terukur. Dengan demikian, meskipun sudah dibatasi, kreativitas pelaku pengabdian masih diberi peluang untuk merumuskan lebih spesifik jenis kegiatan yang detil dan siap dilaksanakan.

Tabel Contoh Pemerincian Program dan Kegiatan

\begin{tabular}{|c|c|c|c|}
\hline & NILAI & INT & TAHUN-1 \\
\hline & 2.28 & {$[2-3]$} & PROGRAM DAN KEGIATAN \\
\hline A. Pengemasan Produk Wisata & A & [2-3] & $\begin{array}{l}\text { 1.A.2. Penyusunan dan sosialisasi produk } \\
\text { wisata jenis tertentu }\end{array}$ \\
\hline $\begin{array}{l}\text { Bentuk kemasan barang } \\
\text { ataupun jasa-jasa wisata yang } \\
\text { ditampilkan }\end{array}$ & \multicolumn{2}{|c|}{$\begin{array}{l}\text { KEGIATAN } \\
\text { SPESIFIK> }\end{array}$} & $\begin{array}{l}\text { Perencanaan dan sosialisasi ekonomi kreatif } \\
\text { berbasis bahan lokal (pangan, pakaian, } \\
\text { kesenian, dsb). }\end{array}$ \\
\hline B. Model Promosi & B & {$[2-3]$} & $\begin{array}{l}\text { 1.B.2. Pengembangan dan sosialisasi model- } \\
\text { model promosi wisata. }\end{array}$ \\
\hline $\begin{array}{l}\text { Pilihan berbagai media } \\
\text { promosi }\end{array}$ & \multicolumn{2}{|c|}{$\begin{array}{l}\text { KEGIATAN } \\
\text { SPESIFIK> }\end{array}$} & $\begin{array}{l}\text { Penyusunan konsep dan aplikasi model } \\
\text { promosi wisata yang profesional dan efektif. }\end{array}$ \\
\hline C. Sistem informasi wisata & C & {$[2-3]$} & $\begin{array}{l}\text { 1.C.2. Pemanfaatan berbagai macam sistem } \\
\text { informasi bekerjasama dengan pihak luar. }\end{array}$ \\
\hline $\begin{array}{l}\text { Kombinasi dari teknologi } \\
\text { informasi dan aktivitas orang } \\
\text { yang menggunakan teknologi } \\
\text { itu untuk mendukung aktifitas } \\
\text { wisata }\end{array}$ & \multicolumn{2}{|c|}{$\begin{array}{l}\text { KEGIATAN } \\
\text { SPESIFIK> }\end{array}$} & $\begin{array}{l}\text { Pengembangan Sistem Informasi Kawasan } \\
\text { Wisata (SIKW) }\end{array}$ \\
\hline D. Distribusi pemasaran & $\mathrm{D}$ & {$[2-3]$} & $\begin{array}{l}\text { 1.D.2. Pengembangan jangkauan pemasaran } \\
\text { sampai tingkat antar propinsi }\end{array}$ \\
\hline $\begin{array}{l}\text { Jangkauan relasi pemasaran } \\
\text { produk wisata }\end{array}$ & \multicolumn{2}{|c|}{$\begin{array}{l}\text { KEGIATAN } \\
\text { SPESIFIK> }\end{array}$} & $\begin{array}{l}\text { Penyusunan dan implementasi konsep } \\
\text { pemasaran skala propinsi }\end{array}$ \\
\hline
\end{tabular}

Dari tabel di atas ini, Program dan Kegiatan diturunkan Kegiatan Spesifik yang dapat dilakukan secara tahunan. Contoh di atas ini menjelaskan aspek pemasaran, pengemasan (unsur 
A, B, C, dan D). Masing-masing unsur aspek, misalnya A (Pengemasan Produk) dengan deskripsi "Bentuk kemasan barang ataupun jasa-jasa wisata yang ditampilkan" dikembangkan lebih lanjut menjadi kegiatan spesifik "Perencanaan dan sosialisasi ekonomi kreatif berbasis bahan lokal (pangan, pakaian, kesenian, dsb)". Artinya, pada tahun pertama harus dilakukan kegiatan "perencanaan dan sosialisasi ekonomi kreatif pangan, pakaian dan kesenian. Rumusan ini lebih nyata sebagai aksi di lapangan. Demikian seterusnya berlaku pada semua aspek. Pembacaannya dapat mengikuti pola yang digambarkan dengan tabel di bawah ini.

Tabel Pemerincian Program dan Kegiatan Tahunan

\begin{tabular}{|c|c|}
\hline \multicolumn{2}{|c|}{ TAHUN-1 } \\
\hline PROGRAM & KEGIATAN SPESIFIK \\
\hline $\begin{array}{l}\text { 1.A.2. Penyusunan dan sosialisasi produk } \\
\text { wisata jenis tertentu }\end{array}$ & $\begin{array}{l}\text { Perencanaan dan sosialisasi ekonomi kreatif } \\
\text { berbasis bahan lokal (pangan, pakaian, } \\
\text { kesenian, dsb). }\end{array}$ \\
\hline $\begin{array}{l}\text { 1.B.2. Pengembangan dan sosialisasi model- } \\
\text { model promosi wisata. }\end{array}$ & $\begin{array}{l}\text { Penyusunan konsep dan aplikasi model } \\
\text { promosi wisata yang profesional dan efektif. }\end{array}$ \\
\hline $\begin{array}{l}\text { 1.C.2. Pemanfaatan berbagai macam sistem } \\
\text { informasi bekerjasama dengan pihak luar. }\end{array}$ & $\begin{array}{l}\text { Pengembangan Sistem Informasi Kawasan } \\
\text { Wisata (SIKW) }\end{array}$ \\
\hline $\begin{array}{l}\text { 1.D.2. Pengembangan jangkauan pemasaran } \\
\text { sampai tingkat antar propinsi }\end{array}$ & $\begin{array}{l}\text { Penyusunan dan implementasi konsep } \\
\text { pemasaran skala propinsi }\end{array}$ \\
\hline
\end{tabular}

\section{KESIMPULAN DAN SARAN}

Kesimpulan: Kegiatan pengabdian masyarakat sebagai implementasi ilmu dan teknologi dari kampus ke dalam kehidupan nyata di kalangan masyarakat perlu diawali dengan pengukuran kondisi awal. Pengukuran yang menjadi awal kegiatan pengabdian masyarakat perlu dilakukan untuk memahami situasi kualitatif maupun kuantitatif yang sesungguhnya dari suatu kawasan jika akan dilakukan intervensi atau pengembangan dalam jangka waktu beberapa tahun. Pengukuran dengan konsep MSPD (Marketability, Sustainability, Praticipatory dan Disaster Mitigation) dapat digunakan untuk mengukur kondisi awal suatu kawasan wisata yang memfokus pada aspek Marketing, Sustainability, Participatory dan Disaster Mitigation.

Rekomendasi atau Saran: Setiap kegiatan pengabdian pada masyarakat, hendaknya diawali dengan pengukuran kondisi awal, berbasis pada konsep atau teori tertentu yang dikembangkan menjadi instrumen pengukuran agar diketahui kondisi awal dan berguna untuk merumuskan penyusunan program serta pemantauannya dalam jangka waktu beberapa tahun. Penyusunan program berbasis teori tertentu yang mewujud menjadi instrumen pengukuran sangat berguna untuk merumuskan program yang tepat dan membantu pengelolaan program intervensi pemberdayaan kawasan dalam jangka panjang secara bertahap-berjenjang dan berkelanjutan.

\section{DAFTAR PUSTAKA}

Dewi, M. H. U. (2014). Partisipasi Masyarakat Lokal dalam Pengembangan Desa Wisata di Kabupaten Tabanan, Bali. disertasi, tidak dipublikasikan, Sekolah Pascasarjana, Universitas Gadjah Mada, Yogyakarta. 
Dewi, M. H. U., Fandeli, C., \& Baiquni, M. (2013). Pengembangan Desa Wisata Berbasis Partisipasi Masyarakat Lokal di Desa Wisata Jatiluwih, Tabanan, Bali. Kawistara, 3(2), 129-139.

Permana, E., Santosa, H. R., \& Soemardiono, B. (2010). Integrasi Pengembangan Wisata Pantai dan Permukiman Nelayan di Pesisir Barat Kabupaten Bengkulu Selatan dalam rangka Konservasi Alam. In Seminar Nasional Perumahan Permukiman dalam Pembangunan Kota 2010 (pp. 1-15). Surabaya: Jurusan Arsitektur ITS.

Priatmodjo, D. (2011). Penataan kota bermuatan antisipasi bencana. Nalars, 10(2), 83-104.

Raharjana, D. T. (2012). Membangun Pariwisata Bersama Rakyat: Kajian Partisipasi Lokal Dalam Membangun Desa Wisata Di Dieng Plateau. Jurnal Kawistara, 2(3), 225-237.

Siswantoro, H., Anggoro, S., \& Sasongko, D. P. (2012). Strategi Optimasi Wisata Massal Di Kawasan Konservasi Taman Wisata Alam Grojogan Sewu. Jurnal Ilmu Lingkungan, $10(2), 100-110$.

Sutrisno. (2016). Predisposisi Partisipasi Masyarakat dalam Perencanaan Kampung Wisata (Studi Kasus Kampung Wisata Santan). Jurnal AGRARIS, 2(1), 36-49.

\section{SESI TANYA JAWAB}

\begin{tabular}{|c|c|c|c|c|}
\hline $\begin{array}{c}\text { Nama } \\
\text { Pemakalah }\end{array}$ & $\begin{array}{c}\text { Nama } \\
\text { Penanya }\end{array}$ & $\begin{array}{c}\text { Asal } \\
\text { Institusi }\end{array}$ & Isi Pertanyaan & Jawaban \\
\hline $\begin{array}{l}\text { Djarot } \\
\text { Purbadi }\end{array}$ & $\begin{array}{l}\text { Patricia } \\
\text { Pahlevi N }\end{array}$ & $\begin{array}{l}\text { UKDW } \\
\text { Yogyak } \\
\text { arta }\end{array}$ & $\begin{array}{l}\text { Apakah dalam } \\
\text { model pengukuran } \\
\text { ini sudah } \\
\text { diperhitungkan } \\
\text { perubahan dalam } \\
\text { masa perencanaan } \\
\text { jangka panjang? } \\
\text { Mungkinkah dalam } \\
\text { suatu waktu dapat } \\
\text { terjadi perubahan } \\
\text { di masyarakat } \\
\text { sehingga } \\
\text { pengukuran awal } \\
\text { dapat begeser atau } \\
\text { kurang sesuai? }\end{array}$ & $\begin{array}{l}\text { Model ini sebenarnya mencoba } \\
\text { masuk ke aspek marketing, dll } \\
\text { seperti yang sudah dijelaskan } \\
\text { mengenai } 4 \text { hal yang sudah } \\
\text { disebutkan saat presentasi. Alat ukur } \\
\text { digunakan untuk melihat perubahan. } \\
\text { Dengan adanya perubahan justru } \\
\text { merasa suka dan tertarik, karena } \\
\text { dapat diketahui hasil pengukurannya } \\
\text { seperti apa. Kalau tidak ada } \\
\text { perubahan justru ada yang salah } \\
\text { dengan programnya. Kalau } \\
\text { pengukuran awal biasanya bersifat } \\
\text { memotret. Barulah berikutnya } \\
\text { dilakukan pengukuran apakah terjadi } \\
\text { perubahan dalam kurun waktu } \\
\text { tertentu. }\end{array}$ \\
\hline
\end{tabular}

